4

\title{
Non-destructive characterisation of the Elephant Moraine 83227 meteorite using confocal Raman, micro-energy-dispersive X-ray fluorescence and Raman-scanning electron microscope-energy-dispersive $\mathrm{X}$-ray microscopies
}

\author{
Imanol Torre-Fdez ${ }^{1,2}$ \& Julene Aramendia ${ }^{1,2}$ \& Leticia Gomez-Nubla ${ }^{1,2}$ \& Kepa Castro ${ }^{1,2}$ \& Maite Maguregui ${ }^{2,3}$ \& \\ Silvia Fdez-Ortiz de Vallejuelo ${ }^{1,2}$ \& Gorka Arana ${ }^{1,2}$ \& Juan M. Madariaga ${ }^{1,2}$
}

Received: 31 July 2018 / Accepted: 5 September 2018

\# Springer-Verlag GmbH Germany, part of Springer Nature 2018

\begin{abstract}
The application of a non-destructive analytical procedure to characterise the mineral phases in meteorites is a key issue in order to preserve this type of scarce materials. In the present work, the Elephant Moraine 83227 meteorite, found in Antarctica in 1983 and originated from 4 Vesta asteroid, was analysed by micro-Raman spectroscopy, micro-energy-dispersive X-ray fluorescence and the Structural and Chemical Analyser (Raman spectroscopy coupled with scanning electron microscopy-energy-dispersive spectroscopy) working in both point-by-point and image modes. The combination of all these techniques allows extracting at the same time elemental, molecular and structural data of the studied microscopic area of the meteorite. The most relevant results of the Elephant Moraine 83227 were the finding of tridymite for the first time in a 4 Vesta meteorite, along with quartz, which means that the meteorite suffered high temperatures at a certain point. Moreover, both feldspar and pyroxene were found as the main mineral phases in the sample. Ilmenite, apatite, chromite and elemental sulphur were also detected as secondary minerals. Finally, calcite was found as a weathering product, which was probably formed in terrestrial weathering processes of the pyroxene present in the sample. Besides, Raman spectroscopy provided information about the conditions that the meteorite experienced; the displacements in some feldspar Raman bands were used to estimate the temperature and pressure conditions that the Elephant Moraine 83227 was subjected, because we obtained both low and high formation temperature feldspar.
\end{abstract}

\section{Keywords Meteorite $\cdot 4$ Vesta $\cdot$ EET $83227 \cdot$ Raman $\cdot$ SEM-EDS $\cdot$ XRF}

Electronic supplementary material The online version of this article (https://doi.org/10.1007/s00216-018-1363-5)contains supplementary material, which is available to authorized users.

$* \quad$ Imanol Torre-Fdez imanol.torre@ehu.eus

1 Department of Analytical Chemistry, Faculty of Science and Technology, University of the Basque Country (UPV/EHU), Barrio Sarriena s/n, 48940 Leioa, Basque Country, Spain

2 Spanish Science Team of the RLS instrument, Exomars 2020 Mission of ESA to Mars, Madrid, Spain

3 Department of Analytical Chemistry, Faculty of Pharmacy, University of the Basque Country (UPV/EHU), P.O. Box 450, 01080 Vitoria-Gasteiz, Basque Country, Spain

\section{Introduction}

The Elephant Moraine 83227 (EET 83227) meteorite was 31 found in the Elephant Moraine icefield of Antarctica in 198332 by the US Antarctic Search for Meteorites program 33 (ANSMET) with a weight of $1973 \mathrm{~g}$. EET 83227 is one of 34 the 268 meteorites classified as a Polymict Eucrite Meteorite 35 $[1,2]$, belonging to the HEDs (Howardites-Eucrites- 36 Diogenites) group of achondritic meteorites [3]. Achondrites 37 are rocks formed on a parent body that suffered a melting 38 process, in which different phases were formed and differen- 39 tiated. Based on spectroscopic data (telescopic visible and 40 near-infrared), eucrites are rocks originated from the asteroid 41 4 Vesta [3-5], having a different oxygen isotopic distribution 42 than the Earth-Moon and Mars meteorites [6].

Polymict eucrites are regolith breccias consisting of eucrite $\quad 44$ fragments and less than one part in ten of diogenite, an 45 
arbitrary dividing line from the howardites, which are related in structure. The typical polymict eucrites are characterised by (a) large medium-grained mafic clasts, containing ophitic to radial pyroxene/Ca-rich plagioclase intergrowths and (b) breccias clasts with shocked pyroxene and twinned feldspar.

Regarding the particular polymict eucrite that was analysed in this study, EET 83227, only the basic characteristics of the specimen are reported in literature following the standard procedures of petrology [1]. There, it was described that coarsegrained lithic fragments, fine-grained granular mafic clasts and rare glassy fragments were found. Moreover, three orthopyroxene grains, more magnesian than $\mathrm{En}_{70}$, were detected by microprobe, diogenite-like clasts were said to be very rare and maskelynite was not observed [1].

Apart from these few data, little is known about the particular mineralogy and geochemistry of the EET 83227 meteorite. This meteorite is expected to be composed of the original material of 4 Vesta asteroid, although it can have varied due to the pressure and temperature conditions suffered during its travel as well as due to the entrance in the terrestrial atmosphere. Moreover, the fact that the meteorite is porous does not allow ruling out reactions among original components of the meteorite and terrestrial compounds present in the landing location, especially if we take into account the terrestrial age of this meteorite, that has been estimated with a minimum of 16.5 Ma [7].

The study of this non-terrestrial body is interesting for two main reasons. On the one hand, it can provide new information about 4 Vesta regarding its origin or formation. Although studies about this asteroid already exist, every single meteorite originated from it can contribute to its understanding, specially taking into account that this type of sample is very scarce. On the other hand, a meteorite analysis does not only contribute to the study of its parent body, but also to the understanding of the different alteration processes that they suffer from the moment they come off from their parent body to the moment they are collected on Earth. In this sense, this kind of studies can provide clues for the understanding of the Solar System and all the processes that take place there. Besides, as it has been wandering through the outer space for a long time, it acts as a historic tracer, helping to understand the Earth origin [8]. Therefore, due to these reasons, the EET 83227 meteorite's analysis is a necessity.

An important part of the studies carried out on nonterrestrial materials is focused on the geochemical and petrochemical analyses. This information is crucial for the elucidation of the different matters explained above. Until some years ago, destructive analytical techniques have been the most used ones for the meteorites' analyses. However, analytical techniques and methods have evolved towards more reliable and sensitive procedures [9]. In that work, authors suggest the use of a combined analytical methodology, employing microRaman spectroscopy and imaging, micro X-ray fluorescence spectrometry and imaging, together with the Structural and Chemical Analyser (Raman spectrometer coupled to SEMEDS), to ascertain the elemental, the molecular (mineralogical in this case due to the absence of organic molecules) and the structural composition. All these analyses can be performed in a non-destructive way, helping in the preservation of these valuable and scarce samples for further studies [9].

Due to the high lateral resolution and confocality of these analytical techniques, inclusions trapped in the bulk of the meteorites can be easily analysed, providing important data not only about the origin of the extra-terrestrial body but also on the terrestrial weathering processes suffered by the meteorite since its arrival until the day it was collected $[10,11]$. The combination of these techniques provides a precise characterisation of the samples, as they complement each other regarding the information they are capable to obtain. Concretely, micro-Raman spectroscopy will be implemented on board of the Exomars 2020 rover to analyse powdered material from samples taken from the surface and inner (up to $2 \mathrm{~m}$ ) parts of the Martian crust with spot sizes of $50 \mu \mathrm{m}$ [12], which proves the suitability of this technique in order to analyse this kind of samples. Furthermore, the combination of the imaging capabilities of both micro-Raman spectroscopy and micro Xray fluorescence spectrometry, allows the measurement of a complete area of the sample, avoiding leaving any space of the surface without analysing. Finally, the Structural and Chemical Analyser (SCA) interface allows performing Raman spectroscopy analysis inside a SEM-EDS chamber, obtaining both elemental and molecular information of the same spot of the sample.

In addition to these techniques, other ones are usually employed for petrological and mineralogical studies. For instance, $\mu$-X-ray diffraction $(\mu$-XRD) is a commonly used methodology that provides precise information about the different mineral phases present in a rock. However, $\mu$-XRD requires the sample to be crystalline in order to obtain the molecular information. Even though 4 Vesta meteorites are rocky and contain crystalline minerals, they are complex samples and can also contain non ordered or amorphous phases which cannot be analysed by means of $\mu$-XRD. In addition, this kind of materials usually have suffered high pressures and temperatures when they enter Earth's atmosphere, which provokes the loss of crystallinity of the minerals. Furthermore, in this type of techniques, a preparation of the sample is usually needed, which involves a physical alteration of it (like grinding, for instance). Therefore, techniques such as $\mu$-XRD were not considered for this study due to the given reasons.

By using the proposed techniques (Raman spectroscopy, $\mu$ XRF and SEM-EDS), the non-destruction of the analysed sample is guaranteed, as well as the acquisition of reliable elemental and mineralogical results in a micrometric scale. Due to this fact, this methodology is very suitable to cover the geochemical analysis of the EET 83227. 


\section{Materials and methods} Johnson Space Center.
For this study, the thin section sample EET 83227-9 (parent 5) was analysed. The specimen, supplied to us by the US Antarctic Meteorite Program, was collected by the Antarctic Search for Meteorites (ANSMET) program. It was curated by the Department of Mineral Sciences of the Smithsonian Institution and Astromaterials Curation Office at NASA

The elemental characterisation of the ETT 83227 meteorite sample was performed by means of the M4 Tornado (Bruker Nano GmbH, Germany) micro-energy-dispersive X-ray fluorescence spectrometer ( $\mu$-ED-XRF), using both single point analysis and map imaging capabilities. The instrument has a microfocus side window Rh tube powered by a low-power HV generator and cooled by air that extends to a maximum voltage and current of $50 \mathrm{kV}$ and $600 \mu \mathrm{A}$ respectively. The micrometric lateral resolution of the instrument, $25 \mu \mathrm{m}$ for the Mo $\mathrm{K}_{\alpha}$-line, is achieved thanks to a poly-cap optics and the spot size varies as a function of the energy, being $17 \mu \mathrm{m}$ at $2.3 \mathrm{KeV}$ and $32 \mu \mathrm{m}$ at $18.3 \mathrm{KeV}$. The map images were collected using a step of $20 \mu \mathrm{m}$ with the $25 \mu \mathrm{m}$ spot, where every single acquisition is represented by a pixel in the images. The M4 Tornado implements an XFlash silicon drift detector with $30-\mathrm{mm}^{2}$ sensitive area and an energy resolution of $145 \mathrm{eV}$ for $\mathrm{Mn}-\mathrm{K}_{\mathrm{\alpha}}$. To perform the focus of the samples two video microscopes are employed, the first one explores the sample under a low magnification $\left(1 \mathrm{~cm}^{2}\right.$ area while the second one performs the final focusing where the analysis will be carried out $\left(1 \mathrm{~mm}^{2}\right.$ area). To improve the detection of the lightest elements $(\mathrm{Z}<16)$, all the $\mu$-ED-XRF measurements (single points and mapping) were acquired always under vacuum conditions (20 mbar). Using this technique, element distribution images of the sample can be obtained. With them, it can be easy to spot zones of interest to guide the other techniques employed.

The mineralogical analyses were performed using microRaman spectroscopy, both in a single point mode and in the spectroscopic imaging mode. Both modes are implemented in the InVia confocal micro-Raman instrument (Renishaw, UK), provided with a $532 \mathrm{~nm}$ excitation laser and Peltier cooled CCD detector $\left(-70{ }^{\circ} \mathrm{C}\right)$. The instrument is coupled to a Leica DMLM microscope (Bradford, UK), using the $50 \times \mathrm{N}$ PLAN (0.75 aperture) and 20× N PLAN EPI (0.40 aperture) objectives, with a $25-\mu \mathrm{m}$ and a $10-\mu \mathrm{m}$ spot size, respectively. The power applied was set, at the source, at a maximum of $50 \mathrm{~mW}$, while on the sample was always less than $20 \mathrm{~mW}$. The spectra were acquired in the range of $100-3200 \mathrm{~cm}^{-1}$, although in the present work, the spectra are shown in a range of $100-1200 \mathrm{~cm}^{-1}$ to present clearly the fingerprint area of the identified compounds in the meteorite specimen. The definitive measurements were performed after an optimization of the best time of exposure and number of accumulations.

The Raman images were obtained with the same spectrometer using the High Resolution StreamLine technology
(Renishaw, UK). The inVia's motorised microscope stage moves the sample beneath the objective so that the laser line is rastered across the region of interest, collecting the data. The dimension and resolution of the maps were determined depending on the aim of the analysis (fast scan or detailed analysis of an area), but the maximum step between spectra was $10 \mu \mathrm{m}$. Details of the working conditions are given elsewhere [13].

The spectrometer was calibrated daily with a silicon chip and its $520.5 \mathrm{~cm}^{-1}$ band. Data acquisition and treatment was carried out by the Wire 4.2 software package by Renishaw. The results were interpreted by comparing the collected Raman spectra with Raman spectra of pure standard compounds of our own databases and with the RRUFF database [14].

In order to obtain morphological, elemental, molecular (mineralogical) and structural results in the same spot, a scanning electron microscope and an energy-dispersive spectrometer coupled to the Raman spectrometer were used. This coupling was carried out through the Structural and Chemical Analyser (SCA, Renishaw, UK) interface. The experimental platform of the SCA system is composed of different instruments: an EVO 40 Scanning Electron Microscope (SEM, Carl Zeiss NTS GmbH, Germany), which is coupled to an X-max energy-dispersive X-ray spectroscopy equipment (EDS, Oxford Instruments, UK), and the described Raman spectrometer. The SEM images were acquired at high vacuum employing an acceleration voltage of $20 \mathrm{kV}$, reaching up to 10,000 magnifications using an SE detector. For the visual analysis of the sample, an electron beam current of $100 \mathrm{pA}$ was used and in order to obtain the EDS information an electron beam current of 200-500 pA was employed. Due to the nature of the analysed sample, the measurements were carried out without carbon coating, as it had enough conductivity to perform the analysis.

The EDS instrument was used for elemental mapping and the analyses were performed using an 8.5-mm working distance, a $35^{\circ}$ take-off angle and an acceleration voltage of $20 \mathrm{kV}$. For the SEM-EDS data collection, the INCA suite 4.13 (Microanalysis Suite, UK) was used. These instruments are coupled to the Raman spectrometer described above through an optic fibre. This fact allows the acquisition of molecular Raman spectra in the same micrometric spot where elemental data was obtained with the EDS. By using this, simultaneous combination of techniques, elemental, mineralogical, and structural information can be extracted at the same time.

\section{Results}

Micro-energy-dispersive X-ray fluorescence

The $\mu$-ED-XRF imaging results for the main elements present in the sample are presented in Fig. 1. The image 

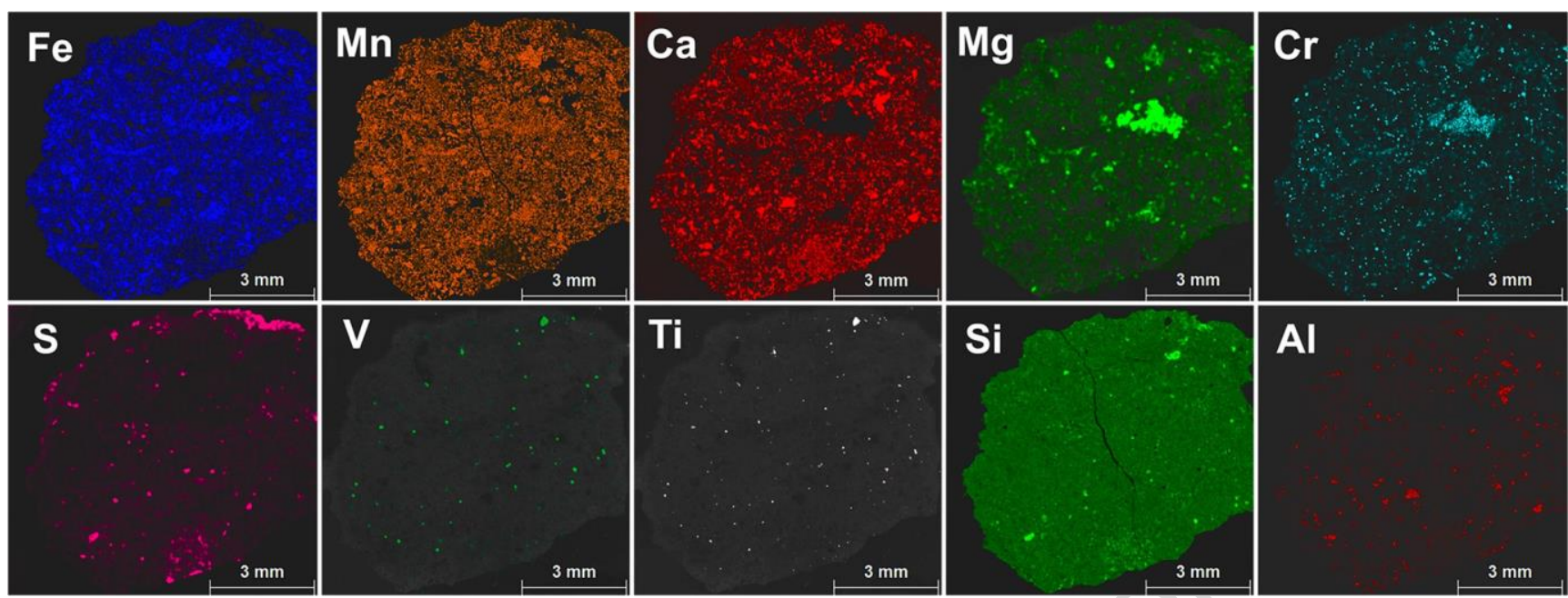

Fig. $1 \mu$-ED-XRF imaging maps for the main elements found in the EET 83227 sample: Fe, Mn, Ca, Mg, Cr, S, V, Ti, Si and Al. The absence of the element in their corresponding map is represented by the absence of

colour, while an increase of the intensity of the colour means a higher relative concentration in that area

was acquired with a step of $20 \mu \mathrm{m}$ between every single measurement, so that the full coverage of the sample surface was guaranteed, as the spot is of $25 \mu \mathrm{m}$. The colour intensity of the mapping for each element image is determined by the intensity of the spectral signal. A brighter colour means a higher intensity of the signal of that element in comparison with the one of the surrounding area. In that sense, several correlations between the different elements could be stablished, observing the presence or lack of an element and its abundance and comparing them with the other ones. This fact can be used to correlate the different elements and help in further Raman spectroscopy mineralogical interpretation.

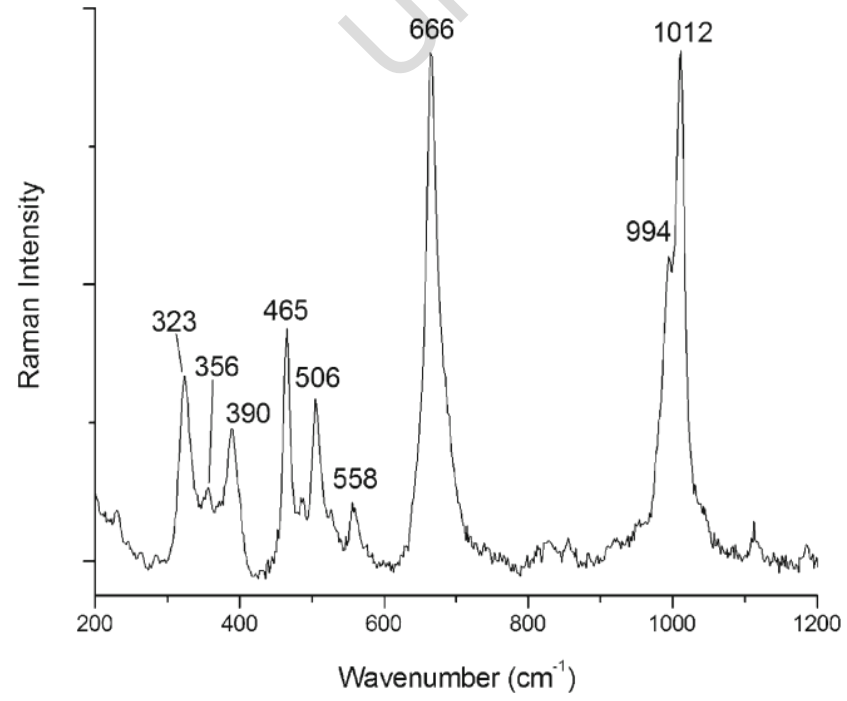

Fig. 2 Pyroxene mixed with quartz Raman spectrum found in the matrix of the sample

\section{Raman spectroscopy}

266

By means of Raman spectroscopy, it was found that one of the main mineral phases of the sample was pyroxene, $\mathrm{XY}(\mathrm{Si}, \mathrm{Al})_{2} \mathrm{O}_{6}(\mathrm{X}=\mathrm{Ca}, \mathrm{Na}, \mathrm{Fe}(\mathrm{II}), \mathrm{Mg}, \mathrm{Zn}, \mathrm{Mn}, \mathrm{Li}$; $\mathrm{Y}=\mathrm{Cr}, \mathrm{Al}, \mathrm{Fe}(\mathrm{III}), \mathrm{Mg}, \mathrm{Co}, \mathrm{Mn}, \mathrm{Sc}, \mathrm{Ti}, \mathrm{V})$, usually mixed with other compounds (Fig. 2). In literature, pyroxene is characterised by the $\mathrm{Si}-\mathrm{O}$ bridging mode at around $1010 \mathrm{~cm}^{-1}$, the Si-O bending mode at $666 \mathrm{~cm}^{-1}$ and the Metal-O stretching at the $300-400 \mathrm{~cm}^{-1}$ range $\left(323 \mathrm{~cm}^{-1}\right.$ for the $\mathrm{Fe}-\mathrm{O}$ stretching in ferrosilite $\left(\mathrm{Fs}, \mathrm{Fe}_{2} \mathrm{Si}_{2} \mathrm{O}_{6}\right)$, $356 \mathrm{~cm}^{-1}$ for the $\mathrm{Ca}-\mathrm{O}$ in wollastonite $\left(\mathrm{Wo}, \mathrm{Ca}_{2} \mathrm{Si}_{2} \mathrm{O}_{6}\right.$ ) and $390 \mathrm{~cm}^{-1}$ for the $\mathrm{Mg}-\mathrm{O}$ in enstatite (En, $\left.\mathrm{Mg}_{2} \mathrm{Si}_{2} \mathrm{O}_{6}\right)$ ). As seen, well resolved stretching bands of the three metals are shown in Fig. 2, indicating the presence of calcium, magnesium, and iron in the pyroxene.

Besides pyroxene, feldspar was also observed as the other main mineral phase in the meteorite sample by means of Raman spectroscopy (Fig. 3). The two strongest bands in feldspar Raman spectra appear in the range of $450-520 \mathrm{~cm}^{-1}$ and correspond to the ring-breathing modes of the four-membered rings of silicate tetrahedron. The bands in the range of $200-300 \mathrm{~cm}^{-1}$ are related to rotation-translation modes of the four-membered rings, while the bands in the $150-200 \mathrm{~cm}^{-1}$ correspond to rotation-translation modes of cage-shear modes. The Raman bands observed in the range of $900-1200 \mathrm{~cm}^{-1}$ are assigned to the vibrational stretching modes of the silicate tetrahedron. Finally, the bands in the 700$900 \mathrm{~cm}^{-1}$ range are related to the deformation modes of the tetrahedron [15].

Silica in two different forms, quartz and tridymite, was also observed by means of Raman spectroscopy. Quartz (465 $\mathrm{cm}^{-1}$ as the main band and 128 and $204 \mathrm{~cm}^{-1}$ as the 

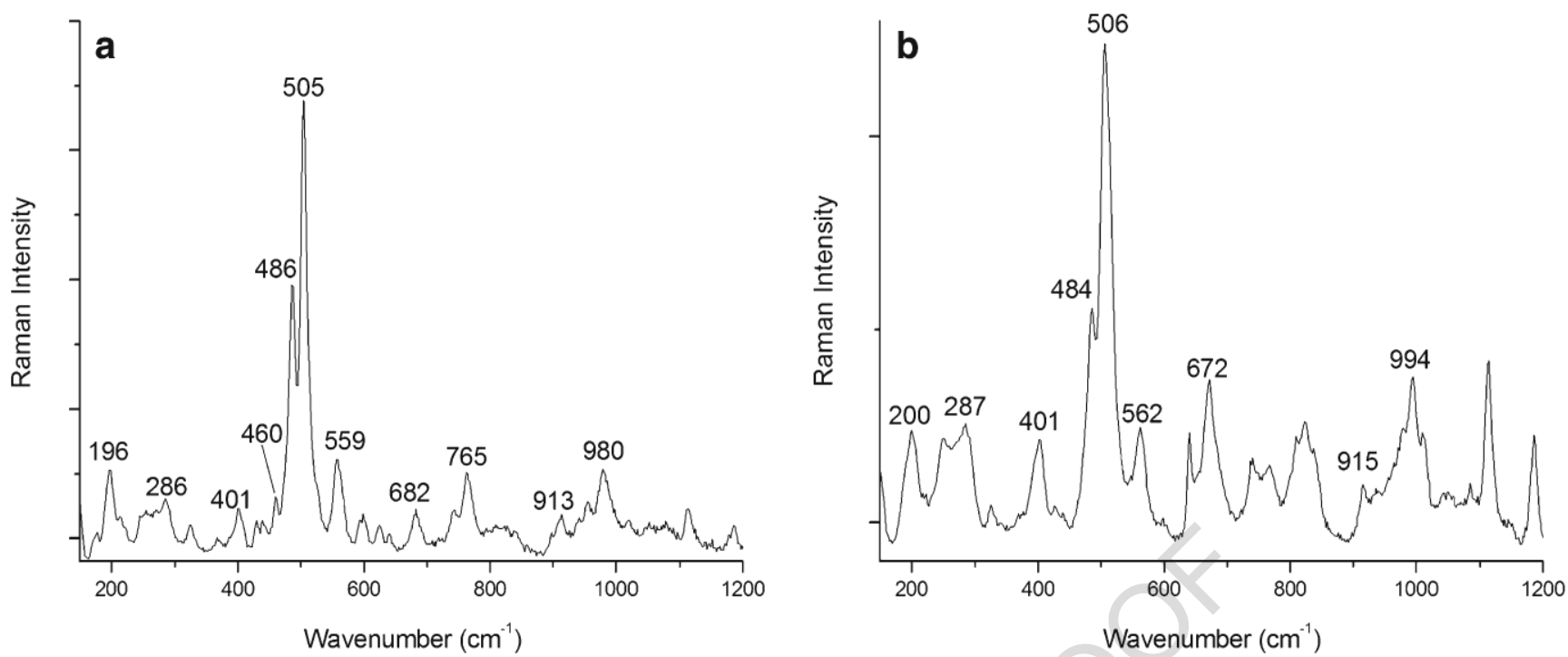

Fig. 3 a Low temperature and b high-temperature Ca-rich feldspar found in the EET 83227 sample by means of Raman spectroscopy

secondary bands, see Electronic Supplementary Material (ESM) Fig. S1) was formed in 4 Vesta after a crystallisation process in liquid water which, probably, came from outside the asteroid [16]. Regardless of the origin of this water, the quartz is an original compound from the meteorite, and not a product of a possible weathering process on the Earth. Together with quartz, tridymite was also found in the EET 83227 sample by means of Raman spectroscopy $(212,307,355$, and $435 \mathrm{~cm}^{-1}$ as the main bands and $793 \mathrm{~cm}^{-1}$ as a secondary band, ESM Fig. S1). This mineral phase is a polymorph of quartz which is formed at low pressure (around 1 bar) and high temperature $\left(>870{ }^{\circ} \mathrm{C}\right)$ conditions [17]. It must be noted that this is the first time that tridymite is observed in a 4 Vesta meteorite and that it has never been reported to be present in the asteroid.

Besides these main mineral phases, three minor compounds belonging to 4 Vesta were found by means of Raman spectroscopy: chromite $(\mathrm{Fe}, \mathrm{Mg}) \mathrm{Cr}_{2} \mathrm{O}_{4}$ $\left(685 \mathrm{~cm}^{-1}\right.$ as the main band), apatite $\mathrm{Ca}_{5}\left(\mathrm{PO}_{4}\right)_{3}(\mathrm{~F}, \mathrm{Cl}$, $\mathrm{OH})\left(963 \mathrm{~cm}^{-1}\right.$ as the main band), and sulphur $\mathrm{S}_{8}(153$, 221 and $472 \mathrm{~cm}^{-1}$ as the main bands and 247 and $439 \mathrm{~cm}^{-1}$ as the secondary bands). Chromite is, along with ilmenite $\left(\mathrm{FeTiO}_{3}\right)$, a known mineral phases that is present in eucritic materials at low concentration in 4 Vesta $(0.3 \%$ for both) [18]. The presence of chromite would explain the chromium hotspot observed previously in the $\mu$-ED-XRF results (Fig. 1). This hotspot matched perfectly with the presence of $\mathrm{Mg}$ and the absence of $\mathrm{Ca}$. In addition, the area also had iron presence. These facts led to the confirmation of a grain of chromite in the sample.

In addition to those major and minor mineral phases, Raman spectroscopy detected in the sample of the EET
83227 meteorite the presence of calcite $\left(\mathrm{CaCO}_{3}\right.$, Raman bands at $1086 \mathrm{~cm}^{-1}$ as the main band and 155,282 , and $713 \mathrm{~cm}^{-1}$ as secondary bands, ESM Fig. S2). Calcite was found systematically along with pyroxene, which appeared in all the spectra where $\mathrm{CaCO}_{3}$ was determined.

\section{SEM-EDS coupled to Raman spectroscopy through the SCA interface}

In order to clarify the pyroxene metallic composition, that is, the abundance of Fs, En and Wo, the SEM-EDS coupled to a Raman spectrometer through the SCA interface was used to characterise the metal proportions of this mineral phase, as shown in literature [19]. Four different pyroxene areas were measured and the mean value of the concentrations for each area was obtained. The metal composition observed in the sample was $\mathrm{Fs}_{22.8} \pm 2.3 \mathrm{En}_{60.2}$ $\pm 4.4 \mathrm{Wo}_{17.0 \pm 1.7}$, where the confidence interval was calculated at a $95 \%$ of confidence and using the standard deviation of the four measured areas.

Moreover, in addition to all the already mentioned minerals, ilmenite was easily found in the meteorite thanks to the capabilities that the SCA interface provides. As it can be observed in Fig. 4, the SEM-EDS measurements performed on the surface of the sample showed some clear Ti hotspots. These hotspots matched perfectly with the $\mathrm{Si}$, $\mathrm{Ca}, \mathrm{Mg}$, and $\mathrm{Na}$ image voids, where they are not present, especially noticeable in the $\mathrm{Si}$ image. In addition, the $\mathrm{Ti}$ hotspots match with the zones where $\mathrm{Fe}$ is in a higher atomic percentage. In fact, both of them have the same colour (light blue) in those zones, which means that they had a similar atomic percentage in the hotspots, that is, the Fe and Ti present in the compound of the hotspots had a 1:1 stoichiometry. This fact was proved with the EDS 

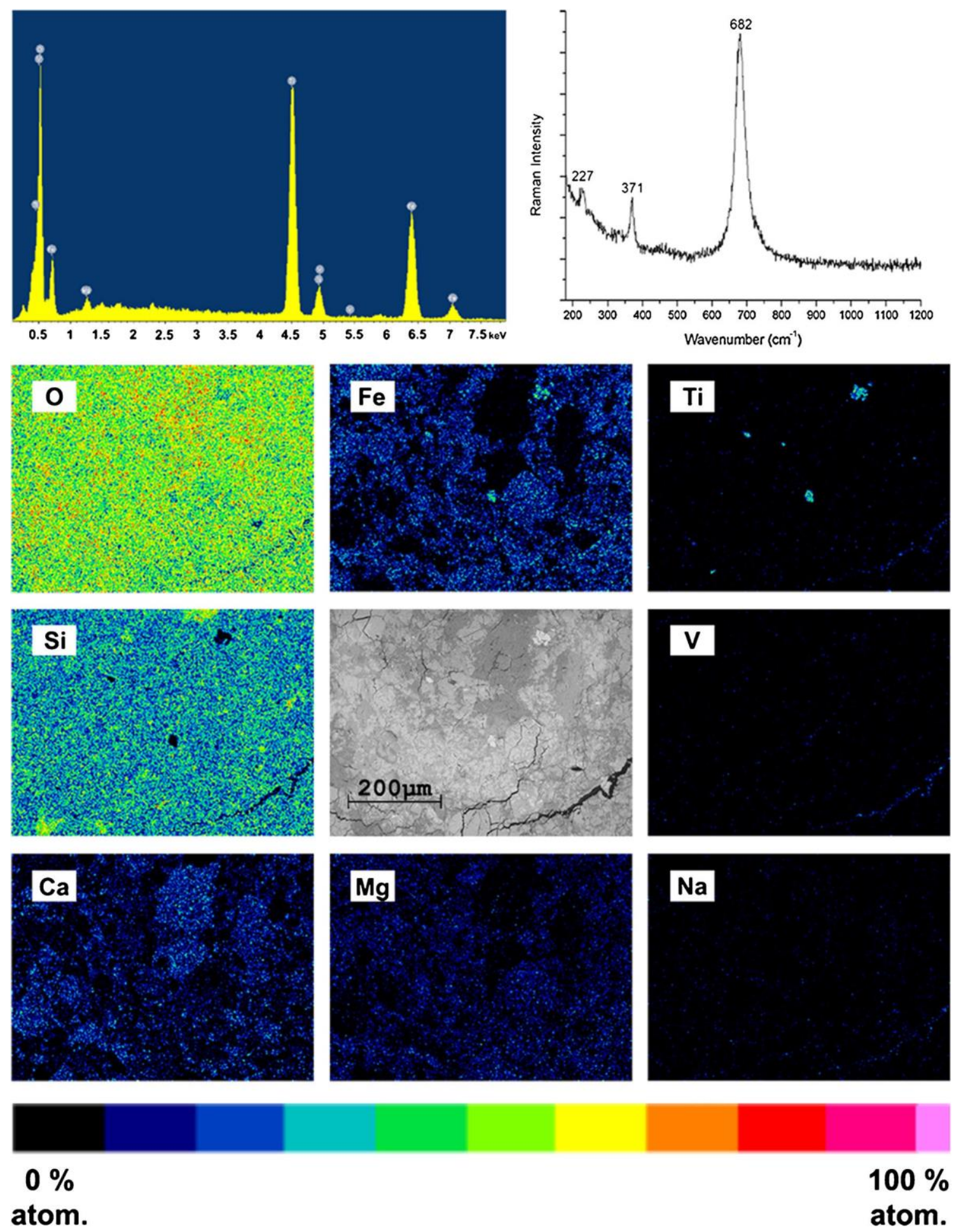

Fig. 4 SEM-EDS and Raman results for a zone of the EET 83227 sample. In the bottom, the EDS images can be observed, measured in atomic percent, with the SEM image in the centre. In the top left, the EDS

results of the named hotspots, which gave a composition of $60.1 \pm 5.9 \%$ for $\mathrm{O}, 18.6 \pm 1.9 \%$ for $\mathrm{Ti}, 19.8 \pm 2.0 \%$ for $\mathrm{Fe}, 1.1 \pm 0.1 \%$ for $\mathrm{Mn}$ and $0.4 \pm 0.1 \%$ for $\mathrm{V}$, measured in atomic percent, and taking into account the standard de-

interval at a $95 \%$ of confidence. In order to obtain mineralogical information of these zones, several Raman spectroscopy measurements were performed thanks to the SCA interface; these spectra corresponded to the ilmenite mineral phase (see Raman spectrum in Fig. 4). 


\section{Discussion}

\section{$\mu$-ED-XRF imaging to discern different mineral phases}

Besides of the usual semi-quantitative results that the $\mu$-ED$\mathrm{XRF}$ analysis provides, the imaging mode of analysis can be used to discern the different mineral phases present in the sample. Each mineral has a different elemental composition, so if the different element maps are compared, the mineral phases can be discerned as a first step in the geochemical characterisation of the sample. In the results shown in Fig. 1, $\mathrm{Si}$ was present through the entire sample, as stone meteorites are composed mainly of silicate minerals. As mentioned in the Introduction, the main mineral phases of the EET 83227 described in literature are pyroxene and feldspar [1, 2]. Al substitutes $\mathrm{Si}$ atoms in the tetrahedral spaces of minerals in a systematic and fundamental way, depending on the mineral nature. The main minerals present in the EET 83227 meteorite, pyroxene and feldspar, suffer from this type of substitution, specially the feldspar. However, according to the Fig. 1, there is not a direct correlation of $\mathrm{Si}$ and $\mathrm{Al}$ along the analysed surface. This could be due to the fact that Al can also be part of the mineral in other spaces, as a cation, according to the general formula of this type of minerals, $\mathrm{XY}(\mathrm{Si}, \mathrm{Al})_{2} \mathrm{O}_{6}(\mathrm{X}=\mathrm{Ca}$, $\mathrm{Na}, \mathrm{Fe}(\mathrm{II}), \mathrm{Mg}, \mathrm{Zn}, \mathrm{Mn}, \mathrm{Li}$; Y=Cr, Al, Fe(III), Mg, Co, Mn, Sc, Ti, V).

Iron, manganese, calcium and magnesium are usually found in this kind of meteorites due to the presence of pyroxene and feldspar as the main mineral phases of eucrites [1]. This is the case of the EET 83227 meteorite. $\mu$-ED-XRF elemental distribution maps (Fig. 1) show a direct correlation between manganese and iron, as it is usual in silicate minerals which have iron as one of the main element [20]. Calcium can have different origins. On the one hand, eucrites have $\mathrm{Ca}$-rich feldspar, which can also explain the absence of potassium and sodium. On the other hand, the presence of pyroxene in this sample could explain the presence of $\mathrm{Ca}$ as well. The analysed EET 83327 meteorite sample (Fig. 1) shows the presence of magnesium through the whole sample, which might be related with the presence of pyroxene, with a hotspot of high magnesium concentration. As this hotspot is not correlated with the calcium distribution map, the presence of magnesium in this specific area is not due to the presence of pyroxene. However, the mentioned hotspot has a correlation with a hotspot of chromium in the same zone, suggesting the presence of another mineral phase besides pyroxene and feldspar.

In the case of sulphur, it was not found any correlation with any of the other elements present in the sample, which might mean that it was present in its elemental state. However, it could also imply the presence of a sulphur or sulphate of an elemental present throughout the whole sample, such as iron. In this sense, a $\mu-X R F$ is not always enough in order to differentiate mineral phases. Finally, the $\mu$-ED-XRF imaging maps for vanadium and titanium had an extremely high correlation, which led to think that a mineral phase composed mainly of $\mathrm{V}$ and $\mathrm{Ti}$ was present in those hotspots.

Raman spectroscopy, results beyond the mineralogical characterisation

As it is known, Raman spectroscopy provides mineralogical information of a given sample in the measured spot, as each spectrum is unique of each mineral. This technique relies on Raman scattering, with which the low frequency modes in a system can be observed, such as the vibrational and rotational modes of a molecule or mineral [21]. This fact means that, besides of the mineralogical characterisation of the sample, Raman spectroscopy can be used to observe other characteristics of the mineral phases.

As it was stated in the "Results" section, pyroxene is one of the main mineral phases of the meteorite. As it is known, there are different types of pyroxenes depending both on their crystalline structure and their calcium, iron and magnesium content in the cation positions [22]. In the Raman spectra (Fig. 2), these structural and chemical differences among pyroxenes can be observed by shifts in the wavenumber of the bands and also in the number or shape of some bands. For example, quadrilateral pyroxenes $\left[\left(\mathrm{Mg}, \mathrm{Fe}, \mathrm{Ca}_{2} \mathrm{Si}_{2} \mathrm{O}_{6}\right]\right.$ present a single strong band near $1000 \mathrm{~cm}^{-1}$, a strong doublet or single band in the range of $600-800 \mathrm{~cm}^{-1}$ and two groups of overlapping bands with moderate intensities in the ranges of 300$450 \mathrm{~cm}^{-1}$ and $450-600 \mathrm{~cm}^{-1}$ [23]. In that work, authors provided accurate results for the content of $\mathrm{Fe}, \mathrm{Mg}$ and $\mathrm{Ca}$ for the quadrilateral pyroxenes by means of Raman spectroscopy [23]. Unfortunately, in the EET 83227 meteorite sample, none of pyroxene Raman spectra collected corresponded to quadrilateral pyroxene, as all of them had a doublet in the 990$1020 \mathrm{~cm}^{-1}$ spectral range, instead of a single intense band. However, with the SEM-EDS it was observed that the elemental composition of the pyroxene of the sample was $\mathrm{Fs}_{22.8 \pm}$ ${ }_{2.3} \mathrm{En}_{60.2 \pm 4.4} \mathrm{Wo}_{17.0 \pm 1.7}$. As it can be seen, the pyroxene present in the EET 83227 meteorite is rich in magnesium and poor in iron and calcium, with calcium being the lowest of them. This ratio of metals in pyroxene is the one that is supposed to have the eucritic crust in 4 Vesta, where pyroxenes are rich in $\mathrm{Mg}$ and specially poor in $\mathrm{Ca}$ [4]. Despite being very similar, the pyroxene composition found in this study has lower concentration of $\mathrm{Mg}$ than the one stated in literature $\left(\mathrm{En}_{70}\right)$ [2].

In the case of feldspar present in the EET 83227 meteorite sample, the determination of its crystalline structure was carried out thanks to Raman spectroscopy based on the work by J. J. Freeman et al. [24]. First of all, it was observed that the feldspar present in the EET 83227 meteorite corresponded to a calcium-rich feldspar. This fact was deduced due to the band that appears at $505 \mathrm{~cm}^{-1}$, which is observed at a lower wavenumber than the Na- and K-rich feldspar, and the low relative 
477 Raman intensity and position for the band at $460 \mathrm{~cm}^{-1}$, which 478 appears with higher relative intensity and at higher 479 wavenumbers for the Na- and K-rich feldspar. This result 480 was in concordance with the ones obtained by $\mu$-ED-XRF 481 described above. Among Ca-rich feldspar, two structurally 482 different feldspars can be differentiated, the low temperature 483 ones, with a primitive unit cell, and the high temperature ones, 484 with a body-centred unit cell [24]. Both types of mineral 485 phases are differentiated by the small band that appears at $486460 \mathrm{~cm}^{-1}$. In the case of a Ca-rich feldspar with a low temper487 ature formation, the band can be observed and visually distin488 guished from the doublet at $486 \mathrm{~cm}^{-1}$ and $505 \mathrm{~cm}^{-1}$ (Fig. 3a). 489
When the band at $460 \mathrm{~cm}^{-1}$ cannot be distinguished without a decomposition of the bands, the Ca-rich feldspar belongs to the high temperature type, with a body centred unit cell [24, Fig. 3b].

Both kinds of feldspar were observed in the EET 83227 meteorite, which led to think that at some point one of the two crystalline types transformed partially into the other one. It is a known fact that low temperature (primitive unit cell) can be transformed into the high temperature one (body-centred unit cell) with high temperatures (around $237^{\circ} \mathrm{C}$ ) or with the increase in sodium content [25]. Although the increase in sodium content cannot be discarded, we do think that the most likely explanation for this alteration is the temperature increase caused by the heat generated when the meteorite entered Earth's atmosphere. In order for this transformation to take place in the crystallographic system of the feldspar, a temperature of at least $237 \pm 1{ }^{\circ} \mathrm{C}$ is needed [26]. High temperatures are reached in the atmospheric entry of celestial bodies. However, in order to estimate the temperature that a meteorite reached when it travelled through the atmosphere, several parameters must be known, such as the shock layer thickness, the mass, the volume or the angle at which the meteorite entered the Earth [27]. On the one hand, some of these are well known, such as the mass (1973.0 g) or the volume $(13 \times 10 \times 9 \mathrm{~cm})$ [2]. On the other hand, the angle at which the meteorite did the atmospheric entry is not known and, although it is stated in the Meteoritical Bulletin that the EET 83227 has a few millimetre-sized patches of fusion crust [2], the exact measurements of the shock layer is not provided. Nevertheless, even though the temperature that the meteorite suffered in the atmospheric entry cannot be estimated, this type of bodies usually suffers temperatures higher than $237{ }^{\circ} \mathrm{C}$ [27]. This fact means that the meteorite's feldspar suffered a partial transformation from a primitive unit cell crystalline structure into a body-centred unit cell one.

In addition to the temperature effect on the feldspar mineral phase, an alteration caused by high pressure on the same mineral phase was also detected. As it can be observed in Fig. 5, the obtained spectra of feldspar are both less resolved and has broader bands than the ones shown in Fig. 3, especially in the $600-1000 \mathrm{~cm}^{-1}$ range. In addition, the band at $980 \mathrm{~cm}^{-1}$ is a little bit wider than the ones mentioned previously. More precisely, it has a full width at half maximum (FWHM) of 32.1, while the FWHM of the same band of the spectrum of Fig. 3a and $b$ is 17.7 and 15.7, respectively. Both the loss of resolution and the widening of the band at $980 \mathrm{~cm}^{-1}$ of a feldspar spectrum are explained by a shocking event that the meteorite suffered [24].

Apart from those two main mineral phases, silica was also observed in the sample in the form of quartz and tridymite. Although quartz is a known compound found in 4 Vesta [17], tridymite has never been previously reported neither in the asteroid itself nor in a meteorite coming from it. This mineral could have been formed through two different ways. On the one hand, it could have been formed in the impact or atmospheric entry of the meteorite on Earth. As it has been already explained above, this event can achieve the necessary temperatures for a mineral phase alteration. In fact, literature states
Fig. 5 Shocked Ca-rich feldspar found in the EET 83227 sample by means of Raman spectroscopy

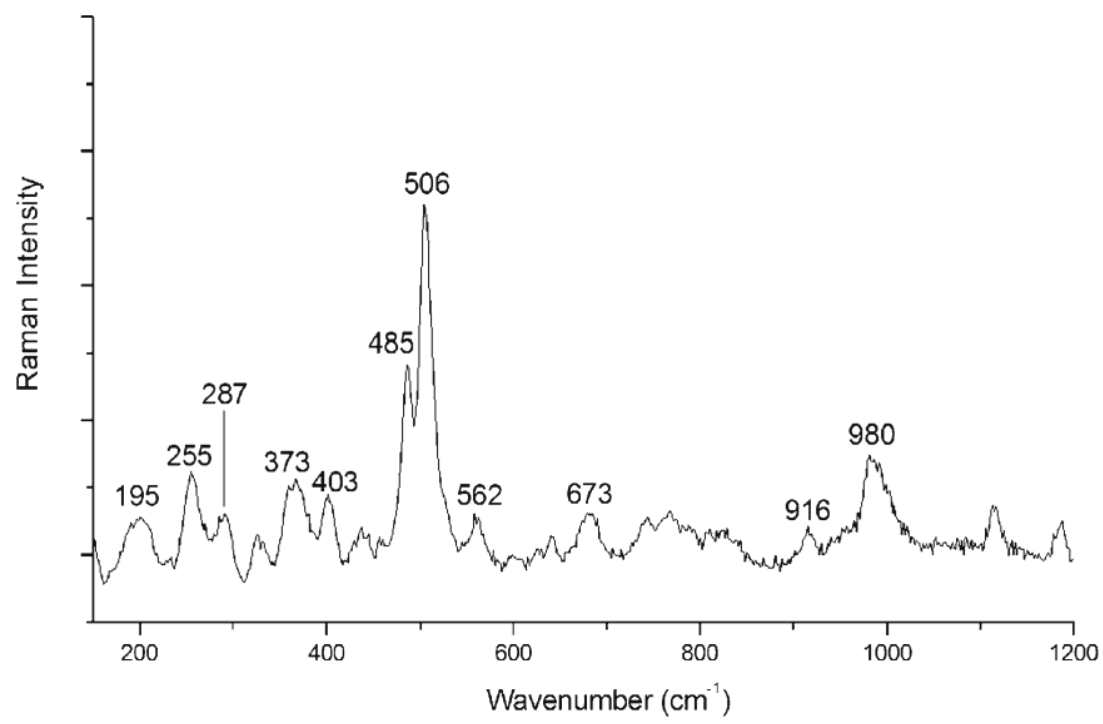


that the impact can generate a temperature up to $2000^{\circ} \mathrm{C}$ [28]. This could lead to the transformation of the quartz present in the meteorite into tridymite. However, this should have been a partial alteration, as quartz was also found in the sample along with tridymite. On the other hand, this polymorph could have been formed in 4 Vesta before the impact that generate the ejecta of the EET 83227 meteorite. As it is known, the asteroid has received through the years, and keeps receiving in the present, numerous impacts of different celestial bodies [29, 30]. These impacts can also transform the quartz present in 4 Vesta into tridymite. Despite tridymite is an uncommon material in Earth, it has been found in Mars by the rover Curiosity [18]; thus, it could have been formed in 4 Vesta through the same process as in Mars, which is still unknown nowadays. However, the two theories explained above have an issue, which is the pressure that the quartz had to suffer. As it has been stated previously, a meteorite impact can generate enough temperature for the transformation, but it can also generate pressure up to $25 \mathrm{GPa}$ [28]. This high pressure would not transform the quartz into tridymite, but into $\beta$-quartz or coesite [31]. Due to this fact, this transformation of quartz into tridymite had to occur at less pressure than $1 \mathrm{GPa}$, regardless if it was formed in 4 Vesta or in the entrance and impact in the Earth, because otherwise coesite would be also present.

The formation of the tridymite mineral phase in 4 Vesta during the geological active period of the asteroid could be a third possible explanation. As it is known, 4 Vesta had once a magma ocean which, gradually, solidified in the asteroid's core and in different geological layers [32]. During this period, tridymite could have formed in a similar way as it is formed on the Earth, appearing in cavities and vesicles of igneous rocks [33]. During that time, there was enough temperature for the formation of this mineral phase, whilst the pressure in its surface was less than $1 \mathrm{GPa}$, due to the small size and therefore very low gravity of 4 Vesta [32].

Regarding the minor mineral phases found in the meteorite sample, some Raman bands of the ilmenite found in the studied EET 83227 meteorite sample did not match with the ones from literature, even though ilmenite is stated in literature to be present in 4 Vesta [19]. At first, it was thought that the mineral found had an ilmenite-type structure, containing vanadium, which would lead to a Raman spectrum that resembled the ilmenite's one with different secondary band position. However, the SEM-EDS results given for the Fe and Ti did not have statistical differences, which would make sense with the presence of ilmenite $\left(\mathrm{FeTiO}_{3}\right)$ and its stoichiometry. In addition, the concentration of vanadium in the hotspots is very low compared to the iron and titanium. These facts led to think that the mineral phase was ilmenite and not an ilmenite-type compound with vanadium. Nonetheless, the vanadium was absent in the entire sample except in these hotspot zones, correlated with titanium, as it was observed in Fig. 1. This vanadium distribution, and the fact that the secondary Raman bands did not match with the literature, led to think that the vanadium was a substituent of the titanium in a small proportion in the mineral phase, which could have led to the different shifts in the Raman spectrum secondary bands.

In addition to the already mentioned mineral phases, calcite was also found in the specimen. As it is known, the formation of this compound in weathering processes usually implies a crystallisation by evaporation from an aqueous solution [34]. The fact that meteorites usually stay long periods of time on the Earth leads them to suffer several terrestrial weathering processes, one of which is the formation of evaporites in their surface and veins [35]. This weathering process has been traditionally explained by the interaction between water, atmospheric $\mathrm{CO}_{2}$ and the original minerals from the meteorite. Reactions involving these three elements take place, transforming the original mineral phases into the altered ones, which are no longer considered extraterrestrial materials [36, 37].

In order to carry out a deeper study of the area where calcite appeared, a Raman chemical image was acquired using the main band of this mineral phase (Fig. 6). As it can be observed, this mineral is present only in an area that is significantly different from the pyroxene/feldspar matrix. This area
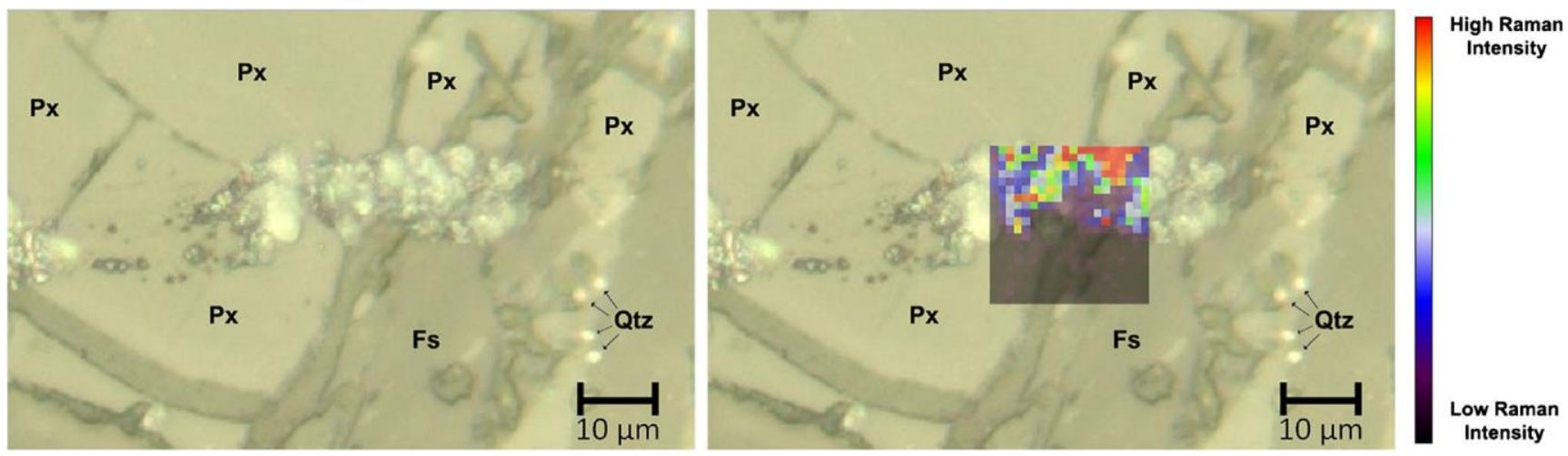

Fig. 6 Raman imaging performed with the $532 \mathrm{~cm}-1$ excitation laser. The morphology of the area analysed (left) together with the calcite Raman image, where the calcite main band was used for the mapping (right) can be observed 
623 does clearly not belong to the original matrix of the meteorite 624 sample, from a visual point of view, and appears as an addition 625 to the surface of the sample. The calcite weathering process 626 can lead to formations of this mineral phase with a similar 627 shape to nanobacteria colonies [38]. In fact, shape and form 628 of the alteration zone of the EET 83227 is very similar to the 629 one that Benzerara presents in his work. He explained the 630 formation of calcite in a similar way as mentioned above, as 631 a process involving water, atmospheric $\mathrm{CO}_{2}$ and original min632 erals from the meteorite. However, he states that biological 633 activity must have taken place in these original minerals in 634 order for the calcite to acquire these unusual formations and 635 shapes. Bacteria and other micro- and nano-organisms usually 636 produce weathering processes in minerals to transform their 637 chemical composition [39]. This alteration of the minerals 638 caused by biological activity could lead to the precursors that, 639 with water and atmospheric $\mathrm{CO}_{2}$, end forming calcite with the 640 unusual nanobacteria-like forms.

\section{Conclusions}

642 The geochemical characterisation of the EET 83227 meteorite 643 performed with non-destructive techniques has contributed to 644 gain a deeper knowledge of the mineral composition present 645 both in the 4 Vesta asteroid and in this particular specimen. In 646 this regard, it was found that the pyroxene present in this 647 sample has a similar composition to the on stated in literature, 648 but with a bit lower Mg content. This fact was not opposed to 649 the theory of 4 Vesta geology and eucrites, as $\mathrm{Mg}$ content 650 remained as the highest and $\mathrm{Ca}$ content as the lowest. 651 Thanks to this finding, it was seen that the use of microscopic 652 analytical techniques focused on specific mineral grains can 653 provide new information in contrast to other techniques that 654 analyse samples as a whole.

655 In addition, it was seen that micro-Raman spectroscopy can 656 provide relevant information about the different conditions 657 that the meteorite has been through. For instance, the evidence 658 of the shock process suffered by the EET 83227 has been 659 observed due to the presence of altered Raman bands in the 660 spectra of feldspar. However, it was deducted the shock did 661 not affect all the meteorite in the same way, leaving some 662 minerals without pressure or temperature alterations, as there 663 were also observed normal feldspar spectra. In addition, 664 Raman spectroscopy was used to determine the crystal system 665 of feldspar and would have been useful to obtain the metallic 666 composition of the pyroxene if they have had been a quadri667 lateral pyroxene. In this sense, it was observed how Raman 668 spectroscopy is a reliable technique not only to obtain the 669 mineralogical characterisation of a specimen, but also to ob-

670 tain results for other factors, such as elemental composition or 671 crystallisation characteristics. However, there is little literature 672 around these aspects of Raman spectroscopy applied into geochemistry, and more research in this field would lead to more obtainable results from the sample solely with his technique, with the same accuracy as other techniques but with a shorter time of analysis.

Moreover, tridymite has been found for the first time in a 4 Vesta meteorite. Although it was not possible to deduce the formation process of it, the most likely explanation is that it was formed in 4 Vesta, when the asteroid still had geological activity. This fact would mean the discovery of tridymite in 4 Vesta. The finding of this mineral phase also demonstrates that the meteorite suffered high temperatures (at least $870{ }^{\circ} \mathrm{C}$ ), but not high pressures. Besides, the identification of tridymite by means of more traditional techniques, such as optical microscopy, would have been difficult. With the combination of the techniques proposed in this work, this finding was possible, which means that the use of this kind of methodology is essential to study extraterrestrial materials, aside from optical microscopy.

As it is usual in meteorites, a weathering process product was observed. Although it does not provide information about the geology of 4 Vesta or the conditions suffered in the atmospheric entrance, their study is crucial. The calcite formations that were observed in the studied sample could lead to misunderstandings in the EET 83227 study. In this case, they were probably formed due to a weathering process that ended up in the transformation of the original pyroxene into calcite, maybe by the action of biological activity.

We would like to highlight the use of SCA technology in the case of the ilmenite determination. Thanks to the fact that it was possible to obtain the elemental and the mineralogical information of single crystals and hotspots, it was possible to unambiguously detect the presence of such mineral. In this sense, it was observed that this methodology has a lot of advantages in the measurement of this type of sample, as it allows performing the elemental and mineralogical characterisation of a micrometric spot in a fast and reliable way.

Acknowledgements This work was financially supported through the project "Development of the Raman instrument for the ESA Mission Exomars2018: Science support, equipment testing and operation support" (ref. ESP2014-56138-C3-2-R) funded by the Spanish Ministry of Economy and Competitiveness (MINECO) and the European Regional Development Fund (FEDER/UE). The thin section sample of the EET 83227 meteorite was kindly provided by the US Antarctic Meteorite Program. US Antarctic meteorite samples are recovered by the Antarctic Search for Meteorites (ANSMET) program, which has been funded by NSF and NASA, and characterised and curated by the Department of Mineral Sciences of the Smithsonian Institution and Astromaterials Curation Office at NASA Johnson Space Center. Authors thank Raman-LASPEA Laboratory from the SGIker (UPV/ EHU, MICINN, GV/EJ, ERDF and ESF) of the University of the Basque Country (UPV/EHU) for their collaboration in the analyses [9].

\section{Compliance with ethical standards}

Conflict of interest The authors declare that they have no conflict of interest. 
1. Antarctic Meteorite Newsletter. 1985. NASA-JSC, Houston.

2. Grossman JN. The meteoritical bulletin, no. 76, 1994 January: the U.S. Antarctic meteorite collection*. Meteoritics. 29:100-43. https://doi.org/10.1111/j.1945-5100.1994.tb00661.x.

3. Binzel RP, Xu S. Chips off of asteroid 4 Vesta: evidence for the parent body of basaltic achondrite meteorites. Science. 1993;260: 186-91. https://doi.org/10.1126/science.260.5105.186.

4. De Sanctis MC, Ammannito E, Capria MT, Tosi F, Capaccioni F, Zambon F, et al. Spectroscopic characterization of mineralogy and its diversity across Vesta. Science. 2012;336:697-700. https://doi. org/10.1126/science.1219270.

5. Magna T, Šimčíková M, Moynier F. Lithium systematics in howardite-eucrite-diogenite meteorites: implications for crust-mantle evolution of planetary embryos. Geochim Cosmochim Acta. 2014;125:131-45. https://doi.org/10.1016/J.GCA.2013.10.015.

6. Scott ERD, Greenwood RC, Franchi IA, Sanders IS. Oxygen isotopic constraints on the origin and parent bodies of eucrites, diogenites, and howardites. Geochim Cosmochim Acta. 2009;73: 5835-53. https://doi.org/10.1016/j.gca.2009.06.024.

7. Herpers U, Vogt S, Bremer K, Hofmann HJ, Suter M, Wieler R, et al. Cosmogenic nuclides in differentiated antarctic meteorites: measurements and model calculations. Planet Space Sci. 1995;43: 545-56. https://doi.org/10.1016/0032-0633(94)00191-S.

8. Crupi V, Giunta A, Kellett B, Longo F, Maisano G, Majolino D, et al. Handheld and non-destructive methodologies for the compositional investigation of meteorite fragments. Anal Methods. 2014;6:6301-9. https://doi.org/10.1039/C4AY00253A.

9. Aramendia J, Gomez-Nubla L, Castro K, Fdez-Ortiz de Vallejuelo S, Arana G, Maguregui M, et al. Overview of the techniques used for the study of non-terrestrial bodies: proposition of novel nondestructive methodology. Trends Anal Chem. 2018;98:36-46. https://doi.org/10.1016/J.TRAC.2017.10.018.

10. Gomez-Nubla L, Aramendia J, Fdez-Ortiz de Vallejuelo S, AlonsoOlazabal A, Castro K, Zuluaga MC, et al. Multispectroscopic methodology to study Libyan desert glass and its formation conditions. Anal Bioanal Chem. 2017;409:3597-610. https://doi.org/10.1007/ s00216-017-0299-5.

11. Gomez-Nubla L, Aramendia J, Alonso-Olazabal A, Fdez-Ortiz De Vallejuelo S, Castro K, Ortega LA, et al. Darwin impact glass study by Raman spectroscopy in combination with other spectroscopic techniques. J Raman Spectrosc. 2015;46:913-9. https://doi.org/10. $1002 /$ jrs. 4700 .

12. Lopez-Reyes G, Rull F, Venegas G, Westall F, Foucher F, Bost N, et al. Analysis of the scientific capabilities of the ExoMars Raman laser spectrometer instrument. Eur J Mineral. 2013;25:721-33. https://doi.org/10.1127/0935-1221/2013/0025-2317.

13. Irazola M, Olivares M, Castro K, Maguregui M, Martínez-Arkarazo I, Madariaga JM. In situ Raman spectroscopy analysis combined with Raman and SEM-EDS imaging to assess the conservation state of 16th century wall paintings. J Raman Spectrosc. 2012;43:1676-84.

the RRUFF project. In: Highlights in Mineralogical Crystallography 2016;1-29.

15. McKeown DA. Raman spectroscopy and vibrational analyses of albite: from $25{ }^{\circ} \mathrm{C}$ through the melting temperature. Am Mineral. 2005;90:1506-17. https://doi.org/10.2138/am.2005.1726.

16. Treiman AH, Lanzirotti A, Xirouchakis D. Ancient water on asteroid 4 Vesta: evidence from a quartz veinlet in the Serra de Magé eucrite meteorite. Earth Planet Sci Lett. 2004;219:189-99. https:// doi.org/10.1016/S0012-821X(04)00004-4.

17. Morris RV, Vaniman DT, Blake DF, Gellert R, Chipera SJ, Rampe $\mathrm{EB}$, et al. Silicic volcanism on Mars evidenced by tridymite in high-
2016;113:7071-6. https://doi.org/10.1073/pnas.1607098113.

18. Zuber MT, McSween HY, Binzel RP, Elkins-Tanton LT, Konopliv AS, Pieters CM, et al. Origin, internal structure and evolution of 4 vesta. In: The Dawn Mission to Minor Planets 4 Vesta and 1 Ceres; 2012. p. 77-93.

19. Torre-Fdez I, Aramendia J, Gomez-Nubla L, Castro K, Madariaga JM. Geochemical study of the Northwest Africa 6148 Martian meteorite and its terrestrial weathering processes. J Raman Spectrosc. 2017;48:1536-43. https://doi.org/10.1002/jrs.5148.

20. Sarbas B, Töpper W. Mn Manganese. Natural Occurrence. Minerals (Native metal, solid solution, silicide, and carbide. Sulfides and related compounds. Halogenides and oxyhalogenides. Oxides of type MO), 8th ed. Springer-Verlag, Berlin, Germany; 1993.

21. Vandenabeele P. Practical Raman spectroscopy - an introduction. Chichester: John Wiley \& Sons, Ltd; 2013.

22. Morimoto N. Nomenclature of pyroxenes. Mineral Petrol. 1998;39: 55-76. https://doi.org/10.1007/BF01226262.

23. Wang A, Jolliff BL, Haskin LA, Kuebler KE, Viskupic KM. Characterization and comparison of structural and compositional features of planetary quadrilateral pyroxenes by Raman spectroscopy. Am Mineral. 2001;86:790-806. https://doi.org/10.2138/am2001-0703.

24. Freeman JJ, Wang A, Kuebler KE, Jolliff BL, Haskin LA. Characterization of natural feldspars by raman spectroscopy for future planetary exploration. Can Mineral. 2008;46:1477-500. https://doi.org/10.3749/canmin.46.6.1477.

25. Gay P, Taylor WH. The structures of the plagioclase felspars. IV Variations in the anorthite structure. Acta Crystallogr. 1953;6:64750. https://doi.org/10.1107/S0365110X53001770.

26. Frey F, Jagodzinski H, Prandl W, Yelon WB. Dynamic character of the primitive to body-centered phase transition in anorthite. Phys Chem Miner. 1977;1:227-31. https://doi.org/10.1007/ BF00307320.

27. Lyne JE, Tauber M, Fought R. An analytical model of the atmospheric entry of large meteors and its application to the Tunguska event. J Geophys Res Planets. 1996;101:23207-12. https://doi.org/ 10.1029/96JE02047.

¿ð. Baziotis IP, Liu Y, Decarli PS, Jay Melosh H, McSween HY, Bodnar RJ, et al. The Tissint Martian meteorite as evidence for the largest impact excavation. Nat Commun. 2013;4:1404. https:// doi.org/10.1038/ncomms2414.

๖. Stephan K, Jaumann R, De Sanctis MC, Tosi F, Ammannito E, Krohn K, et al. Small fresh impact craters on asteroid 4 Vesta: a compositional and geological fingerprint. J Geophys Res E Planets. 2014;119:771-97. https://doi.org/10.1002/2013JE004388.

sv. Clenet H, Jutzi M, Barrat JA, Asphaug EI, Benz W, Gillet P. A deep crust-mantle boundary in the asteroid 4 Vesta. Nature. 2014;511: 303-6. https://doi.org/10.1038/nature13499.

21 Ford MH, Auerbach SM, Monson PA. On the mechanical properties and phase behavior of silica: a simple model based on low coordination and strong association. J Chem Phys. 2004;121: 8415-22. https://doi.org/10.1063/1.1797979.

3) Righter K, Drake MJ. A magma ocean on Vesta: Core formation

1997;32:929-44. https://doi.org/10.1111/j.1945-5100.1997. tb01582.x.

33. Klein C, Philpotts AR, Anthony R. Earth materials : introduction to mineralogy and petrology. 2nd ed. Cambridge: Cambridge University Press; 2017.

34. Neuendorf KKE, Mehl JP, Jackson JA. The glossary of geology. 5th ed. Alexandria: American Geological Institute; 2005.

35. Losiak A, Velbel MA. Evaporite formation during weathering of Antarctic meteorites-a weathering census analysis based on the ANSMET database. Meteorit Planet Sci. 2011;46:443-58. https:// doi.org/10.1111/j.1945-5100.2010.01166.x. 
856

857

858

859

860

861

862

863

871
36. Jull AJT, Cheng S, Gooding JL, Velbel MA. Rapid growth of magnesium-carbonate weathering products in a stony meteorite from Antarctica. Science. 1988;242:417-9. https://doi.org/10. 1126/science.242.4877.417.

37. Liu T, Bish DL, Socki RA, Harvey RP, Tonui E. Mineralogy and formation of evaporite deposits from the Lewis Cliff ice tongue, Antarctica. Antarct Sci. 2015;27:73-84. https://doi.org/10.1017/ S0954102014000406.
38. Benzerara K, Menguy N, Guyot F, Dominici C, Gillet P. 864 Nanobacteria-like calcite single crystals at the surface of the 865 Tataouine meteorite. Proc Natl Acad Sci USA. 2003;100:7438- 866 42.https://doi.org/10.1073/pnas.0832464100.

39. Uroz S, Calvaruso C, Turpault MP, Frey-Klett P. Mineral weathering by bacteria: ecology, actors and mechanisms. Trends Microbiol. 2009; 17:378-87. 
856

857

858

859

860

861

862

863

871
38. Benzerara K, Menguy N, Guyot F, Dominici C, Gillet P. Nanobacteria-like calcite single crystals at the surface of the Tataouine meteorite. Proc Natl Acad Sci USA. 2003;100:743842.https://doi.org/10.1073/pnas.0832464100.

39. Uroz S, Calvaruso C, Turpault MP, Frey-Klett P. Mineral weathering by bacteria: ecology, actors and mechanisms. Trends Microbiol. 2009;17:378-87. 
